\title{
RISK ASSESSMENT OF STEEP SLOPE USING DRONE MAPPING AND TERRESTRIAL LiDAR IN KOREA
}

\author{
S. S. Kim ${ }^{1}$, D. Y. Kim ${ }^{1}$, H. Nho ${ }^{1}$ \\ ${ }^{1}$ National Disaster Management research Institute, 365 Jongga-ro, Jung-gu, Ulsan, 44538, Rep. of Korea - (sskim73, sdy718, \\ nhj1017)@korea.kr
}

Commission IV

KEY WORDS: Steep slope, Risk assessment, Drone mapping, Terrestrial LiDAR

\begin{abstract}
:
Due to abnormal weather caused by climate change in recently years, natural disaster damages caused by local torrential rains have been increased over the world. Particularly, Korea is very vulnerable to landslide disasters because more than $63 \%$ of the country is mountainous and it suffers from unpredictable localized heavy rainfall during monsoon season every year. This paper presents experimental results for risk assessment of steep slope using drone mapping and terrestrial LiDAR survey. First, we acquired the aerial imagery of steep slope site by small UAV and conducted a drone mapping process with the Pix4D software. For collecting the more detailed geological data and analysing quantitatively damage of steep slopes (crack length, bedrock weathering area, etc.), we scanned steep slope area using terrestrial LiDAR system. Finally, we evaluated the applicability of public safety for outputs of UAV photogrammetry and 3D point clouds derived from terrestrial LiDAR data to analyse and assess the risk of steep slope.
\end{abstract}

\section{INTRODUCTION}

\subsection{Overview}

Due to abnormal weather by climate change recently, natural disaster damages caused by heavy rains have been increased over the world. Since meteorological observation began in Korea, the rainy season in 2020 was recorded as the longest period lasting more than 50 days. In particular, due to the topographical characteristics of the Korean peninsula and the rainy season front formed with a narrow width in the east-west directions and a long shape in the north-south directions, natural disasters caused by localized heavy rain are occurring nationwide.

Korea is very vulnerable to landslide disasters because more than $63 \%$ of the country is mountainous and the depth of its soil layer is shallow. As artificial slopes built in the process of urbanization and road facilities such as stone blocks, retaining walls etc. increase, the collapse of steep slopes and damage from landslides have become major damage factors, accounting for about $26 \%$ of the deaths from natural disasters in the last 10 years. There were 164 cases of rockfall collapse on steep slopes in the last 7 years from 2012 to 2018 . In terms of time, $26.2 \%$ is occurred during the thaw season when the soil layer starts to melt, and $65.9 \%$ during the rainy season, so it is necessary to take a precautionary measures in the phase of disaster prevention.

According to the $\ulcorner$ Prevention of Steep Slope Disaster Act $\lrcorner$ in Korea, the steep slope is defined as follows: firstly, natural slopes and artificial slopes (including retaining walls, ledges, etc.) attached to residential land, roads, railroads and park facilities, or secondly, a mountainous area in contact with them, 1) an artificial slope with a height of $5 \mathrm{~m}$ from the ground and a slope of 34 degrees, and a length of $20 \mathrm{~m}$.

2) a natural slope with a height of $50 \mathrm{~m}$ more above the ground and a slope of 34 degrees.

3) other artificial slopes, natural slopes managed by a steep slope management institution or local government under Article
16 (1) of $\ulcorner$ the Framework Act on Disaster and Safety Management $\lrcorner$.

According to Article 5 of $\ulcorner$ Prevention of Steep Slope Disaster Act $\lrcorner$, the safety inspection of steep slopes is prescribed to be carried out at least twice a year by local governments or management agencies. Safety field investigation is basically conducted using steep slope-related data and field survey activity, and classified into regular checks, precise inspection, emergency inspection, and precise safety investigation according to the risk level of steep slope. In this paper, regular inspection is conducted as a way of precautionary activities before the rainfall period of Korea, focused on the field investigation using the advanced investigation platform such as UAVs, Terrestrial LiDAR etc.

\subsection{Related Works}

The use of state-of-the-art observation platform such as such as LiDAR mapping system and drones for topographic mapping enables the collection of high-precision spatial information and analysis based on spatial information in the event of a natural disaster.

Unmanned Aerial Vehicles (UAVs) with various built-in sensors are considered to be almost real-time and cost-effective tools for large-scaled aerial mapping. Its suitability to mapping applications is dependent on mapping extent, geometric accuracy, the durability such as flight time and control distance, and the heavy lifting capacity of UAVs (Kim et al, 2019). UAVs with the GNSS/IMU, gyroscopes, accelerometers, and barometer enable direct geo-referencing and mapping. Precise time-tagging of the camera shutter and GNSS time make it to annotate the position and attitude information as the metadata of captured imagery (Rehak et al., 2013). To save time and manpower for slope inspection filed work, Shin et al. (2019) suggested an approach that evaluated the rapid and accurate steep slope risk by using a terrestrial LiDAR.

Drone mapping is an efficient tool to acquire the newest map and spatial information at inaccessible disaster fields. However, because the low precision of UAVs navigation devices can 
affect the accuracy of the final map products, it is necessary to conduct a minimum GCPs survey or to utilize a RTK-drone or a PPK drone for improving the mapping accuracy. It also needs technologies to analyse quantitative damage level such as damaged area and landslide runoff distance etc. by fusing data between outputs derived from drone mapping and high resolution terrestrial LiDAR point clouds.

In this paper, we acquired drone aerial imagery of steep slope site around and conducted a drone mapping to obtain 3D point clouds, DEM and ortho-imagery of the study area using the Pix4D software. For collecting the more detailed geological data and analysing quantitatively damage of steep slopes (crack length, bedrock weathering area, etc.), we scanned steep slope area using terrestrial LiDAR system. Finally, we evaluated the applicability of public safety for outputs of UAV photogrammetry and 3D point clouds derived from terrestrial LiDAR data to analyse and assess the risk of steep slope.

\section{DISASTER INVESTIGATION PLATFORMS OF NDMI}

\subsection{Investigation vehicle}

Since 2013, National Disaster Management research Institute (NDMI) of the Ministry of Interior and Security (MOIS) has implemented researches and developments for disaster scientific investigation (DSI). DSI, a highly organized framework to reveal the root cause of disasters, aims to implement, monitor and feedback with disaster profiling through state-of-the-art forensic technologies. As the feasible operational tools for DSI, NDMI developed a disaster investigation platform that converted a van in 2015 to investigate effectively and systematically the damage and the cause of a variety of disaster accident. This investigation vehicle is equipped with various disaster accident field investigation sensors such as MMS (Mobile Mapping System) with terrestrial LiDAR that can acquire 3D point cloud data during normal running speed, high resolution optical and thermal imaging cameras, and weather observation equipment as shown Table 1 (Kim et al, 2018).

In particular, RieGL's VZ-2000 with on-board GPS/IMU mounted on the investigation vehicle enables an investigator of a disaster site to obtain high-precision 3D LiDAR data at pre- or post-disaster areas. It can be used to extract terrain data and monitor for steep collapse risk, or detect potholes on existed roads that surface of road has caved in. It is also equipped with an integrated data processing system that can receive and see aerial imagery captured from UAVs to vehicle in real time and transmit it to NDMI by connecting the vehicle and inside laboratory of institute through LTE-network.

\begin{tabular}{|c|l|c|}
\hline Device & \multicolumn{1}{|c|}{ Model } & Unit \\
\hline \multirow{2}{*}{ Optic sonsors } & - HD Bullet Camera 2.0MP & 5 \\
\cline { 2 - 3 } & $\begin{array}{l}\text { - HD Pro camera 4.5K (Avigilon) } \\
\text { - Canon EF Lens 70-200 mm f/2.8L }\end{array}$ & 1 \\
\hline LiDAR system & - RieGL VMZ IMU/GNSS Unit & 1 \\
\hline Thermal sensor & - TPV-IBD & 1 \\
\hline Weather device & - Weatherpak-2000 & 1 \\
\hline Pothole detector & - RoadEye & 1 \\
\hline
\end{tabular}

Table 1. Sensors mounted on investigation vehicle of NDMI

\subsection{Commercial UAVs}

In this study, we used a commercial quadcopter, DJI Mavic 2 Enterprise Dual that is equipped with multiple MEMS and supports autopilot function to perform stable and autonomous flights. This small drone has also a built-in dual sensor: an optic sensor and an FLIR radiometric thermal imaging sensor. The optic sensor is an $24 \mathrm{~mm}$ camera with a $1 / 2.3$ " $12 \mathrm{MP}$ and can capture up to UHD $4 \mathrm{~K}$ video at $30 \mathrm{fps}$. These dual sensors make it more flexible to a variety of public safety applications such as building collapse site investigation or utilities safety inspection etc.

\begin{tabular}{|l|c|}
\hline Weight & $0.89 \mathrm{~kg}($ battery, gimbal included) \\
\hline Dimensions(folded) & H84 $\times$ W91 $\times$ L214(mm) \\
\hline Max Flight time & $31 \mathrm{~min}$. \\
\hline Max. Flight Altitude & $45 \mathrm{mph}(72 \mathrm{kph})$ \\
\hline Max. operation Range & $8 \mathrm{~km}$ \\
\hline Sensor type & Sony $1 / 2.3$-inch CMOS sensor \\
\hline Image size & $12 \mathrm{M}$ \\
\hline Lens aperture & $\mathrm{f} / 2.8 \sim \mathrm{f} / 3.8$ \\
\hline Shutter speed & Electronic shutter, 8 -1/8000s \\
\hline Video size & UHD 4K \\
\hline
\end{tabular}

Table 2. Specifications of DJI Mavic 2 Enterprise Dual

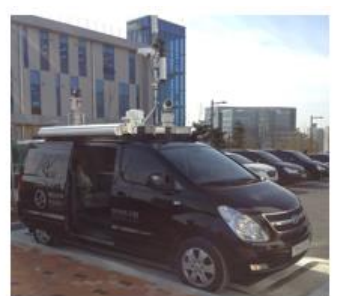

(a) Investigation vehicle of NDM

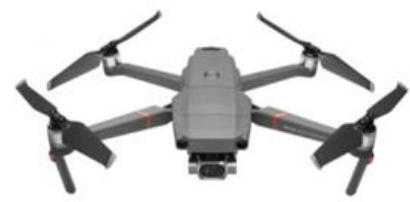

(b) DJ Mavic 2 Enterprise Dual
Figure 1. Disaster investigation platforms in this study

\section{STUDY AREA AND METHOD}

\subsection{Study Area}

Among more than 30 vulnerable areas of steep slopes nationwide that were inspected by the MOIS in June 2020, two sites are selected as high risk steep slope fields that are necessary to closely inspect and manage intensively and regularly: Arirang District of Iksan in Jeollabuk-do, and Mado District of Taean in Chungcheongnam-do (Figure 2). The Arirang district is a rock-formed natural slope and has not been evaluated for slope disaster risk. During the on-site inspection, a number of rocks dropped around rockfall fences and bedrock was destroyed by covered plants and growing trees.

The Mado district is also a rock-formed natural slope field and is evaluated as a D-class disaster risk, and was designated and managed as a collapse risk district in August 2016. According to the report, the rock mass with steep slope was very weaken due to weathering and the bedrock cracks caused by the inclination, and the vegetation density was severe, so it was worried as an area where a rockfall damage is a concern. 


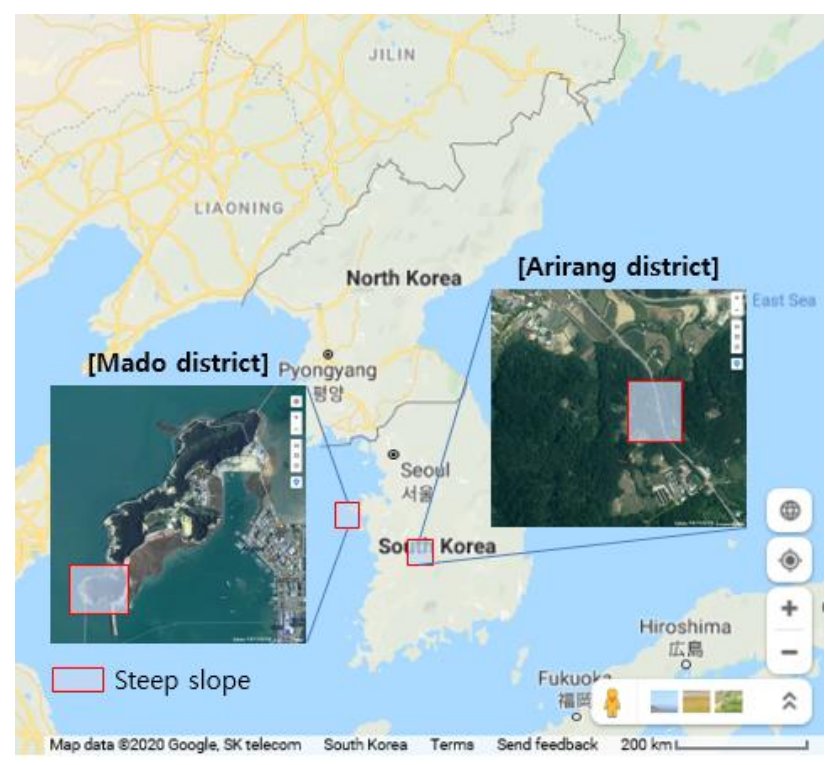

Figure 2. Site location of steep slope in this study

\subsection{Slope risk assessment process}

Regular inspection for steep slope field is conducted generally at the level of visual inspection based on the geological experience and knowledge of experts, using simple inspection equipment such as a tape measure and camera to determine the defects and functional conditions of the slope at the view of geology, and to check whether the prevention facilities such as barrier, drainage line, retaining wall, etc. that satisfies the current requirements for use or not. At this time, careful attention is required to observe the overall appearance of the prevention facilities, and to detect possible serious damage or defects.

In the stage of field investigation using advanced equipment such as drones and LiDAR, first, the field equipment operation plan is established, and GCPs are placed around the slope site and RTK-GNSS survey is performed. Next, for the drone mapping, flight planning, aerial imagery capturing, and drone mapping data process are conducted sequentially. At the same time, for an optimal ground LiDAR data scanning, the number and the location of LiDAR scan station are determined in consideration of the site conditions, and then only point data of the bedrock are extracted by removing noise such as trees and rockfall fences etc. Quantitative geological analysis such as slope degree and rock section analysis is performed using the extracted bedrock point data.

In general, since visual investigation accuracy may be low and subjective opinion may be strong, cross check is indispensable. In the case of visual inspection, the site survey should be conducted after understanding related geotechnical data of slope site and determine and major survey items in advance. The overall work flow of slope risk assessment in this study is shown in Figure 3 below.

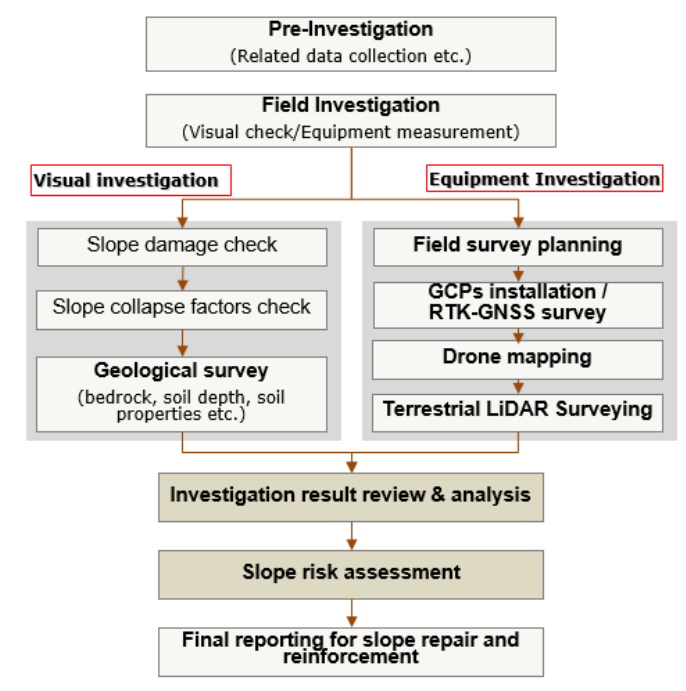

Figure 3. Work flow of slope risk assessment

\subsection{Field survey}

\subsubsection{Drone mapping survey}

On each site, GCPs have been measured at high precisions as shown in Table 3 using RTK-GNSS survey: 5 GCPs at Arirang district and 8 GCPs at Mado district (Figure 4).

We planned to capturing aerial imagery at flight heights of $120 \mathrm{~m}$. A total of 147 images were acquired at two slope sites: 74 images at Arirang district and 73 images at Mado district, respectively. The risk analysis for steep slope is carried out using 3D map data (Point Cloud, DSM/DEM), Ortho-imagery based on location-based GIS data derived by using Pix4D Mapper as shown in Figure 6.

\begin{tabular}{|c|c|c|c|c|c|}
\hline \multicolumn{3}{|c|}{ Arirang district } & \multicolumn{3}{c|}{ Mado district } \\
\hline GCP & $\begin{array}{c}\text { Horizontal } \\
\text { accuracy } \\
(\mathrm{X} / \mathrm{Y})\end{array}$ & $\begin{array}{c}\text { Vertical } \\
\text { accuracy } \\
(\mathrm{Y})\end{array}$ & GCP & $\begin{array}{c}\text { Horizontal } \\
\text { accuracy } \\
(\mathrm{X} / \mathrm{Y})\end{array}$ & $\begin{array}{c}\text { Vertical } \\
\text { accuracy } \\
(\mathrm{Y})\end{array}$ \\
\hline No.1 & 0.013 & 0.015 & No.1 & 0.008 & 0.013 \\
\hline No.2 & 0.048 & 0.064 & No.2 & 0.01 & 0.017 \\
\hline No.3 & 0.315 & 0.318 & No.3 & 0.007 & 0.011 \\
\hline No.4 & 0.047 & 0.056 & No.4 & 0.006 & 0.009 \\
\hline No.5 & 0.029 & 0.048 & No.5 & 0.015 & 0.023 \\
\hline & - & - & No.6 & 0.015 & 0.024 \\
\hline & - & - & No.7 & 0.014 & 2.286 \\
\hline & - & - & No.8 & 0.011 & 0.019 \\
\hline
\end{tabular}

Table 3. Accuracy of GCPs survey each study site
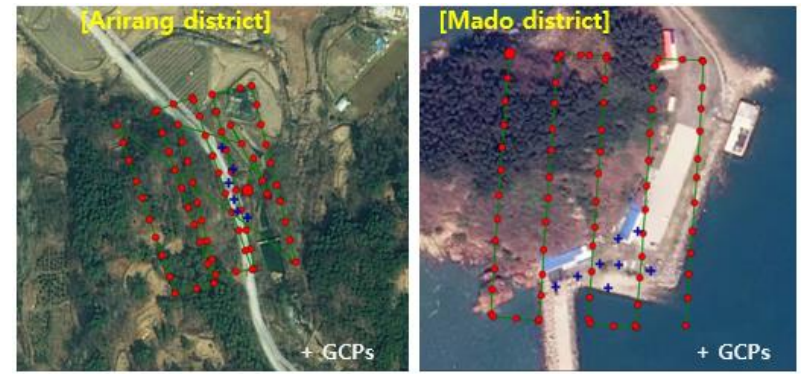

Figure 4. Drone flight path \& Location of GCPs 


\subsubsection{Terrestrial LiDAR survey}

The terrestrial LiDAR used in this study is RIEGL's VZ-2000 that is equipped on the investigation vehicle and provides mobile mapping function as mentioned in 2.1 above. Because the steep slope in this study are difficult to scan at once due to height and size of target slope, laser scanning was performed 3 to 5 times each district, respectively. More 200 million points data were acquired through laser scanning of steep slopes. After removing points related to vegetation and noise, accurate DEM data were finally generated for risk assessment.
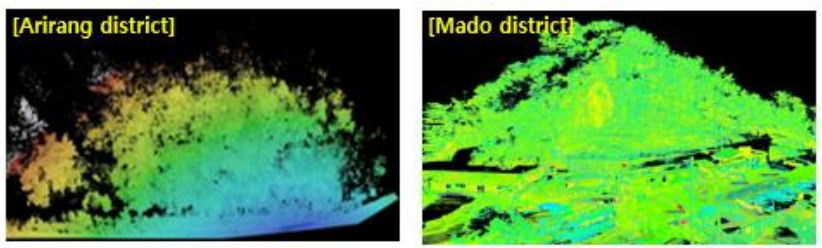

(a) Point clouds derived from LiDAR survey on study sites
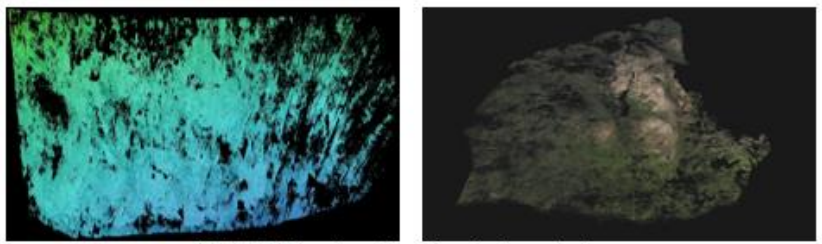

(b) Point cloude extraction for target slope
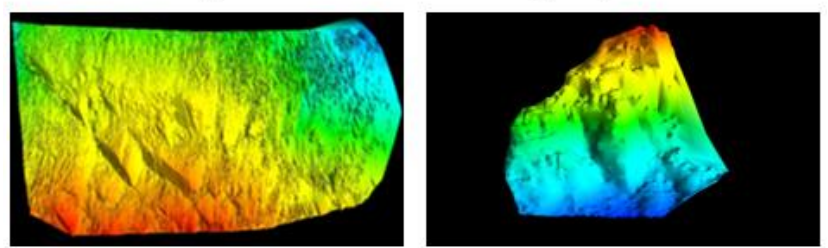

(C) Final DEM of target slope after noise filtering

Figure 5. Steep slope outputs through LiDAR data processing

\section{RESULTS AND DISCUSSION}

\subsection{Slope risk analysis using drone mapping}

As more precise RTK-GNSS, navigation devices, and highresolution optical sensors have been installed, commercial small drones can take remote close-up imagery or implement drone mapping for disaster situation awareness at inaccessible disaster field such as landslides and building collapses. It can be the rapid and timely tools for 3D spatial information collection and damage analysis tasks such as change detection using spatial information of pre- and post- disaster. In this paper, a UAV photogrammetry technique using a small drone was applied to take close-up aerial imagery of the natural slopes of steep slopes that are difficult to access directly by the investigator and to acquire and analyse spatial information on the top of slope or around the slope that are difficult to be obtained by terrestrial LiDAR (Figure 6).

\subsubsection{Arirang site}

From drone aerial imagery and outputs of drone mapping around the steep slope of Arirang district, it was confirmed that there were two cemeteries and access roads at the top of the target slope. A family memorial park is built at $150 \mathrm{~m}$ distance along Arirang-ro, and a large-scale livestock facility was located at $250 \mathrm{~m}$ distance toward the top of a mountain. In particular, the cemetery built on the top of the natural slope satisfies the conditions in which direct external force, i.e. the insufficient drainage of the slope, could be occurred during the rainy season or a short-term torrential rain. Also, in the process of site inspection conducted in mid-June, high-density of vegetation makes it be difficult to collect aerial imagery from the drone and extract the slope surface data by causing that plants and trees occluded target bedrock.

\subsubsection{Mado site}

Mado district was turned out that rockfalls occurred in three spots on the target slope in processing the risk analysis of target slope using drone aerial imagery and outputs from drone mapping.

Area A is concerned that a large-scale rockfall will occur due to joint surfaces and cracks caused by vegetation. Area B is considered to have a high probability of potential rockfall by being in progress of surfaces crack and fault joints. Area $\mathrm{C}$ was also judged a high risk of rockfall because the vegetationinduced cracks were developed in the rock mass with a very steep slope and severe weathering relatively.

As taking a closer look, bedrock cracks and rock dropouts were observed due to external pressure due to the shallow surface layer of the upper part and woody species (A-1, A-2). As explained in detail via processing results of LiDAR data, it was observed that the crack width of the joint surface of A-2 cracked due to vegetation spontaneous growth was about $5 \mathrm{~cm}$ and the length was $1.1 \mathrm{~m}$. In addition, in the lower part A-3 rock mass, the crack width caused by joint is observed to be about 17 to 35 $\mathrm{cm}$, and cracks caused by joint (about 5 to $8 \mathrm{~cm}$ ) are observed to progress in the A-4 rock mass (Figure 7).

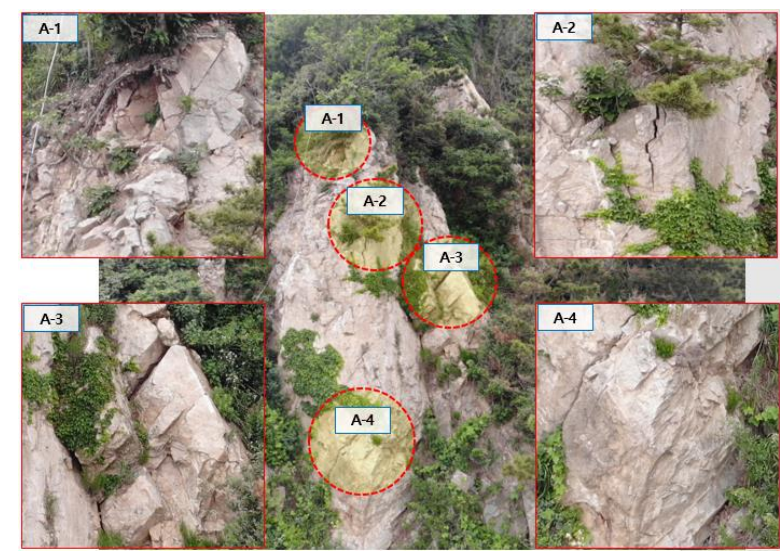

Figure 7. Close-up captured drone aerial imagery of inaccessible steep slope
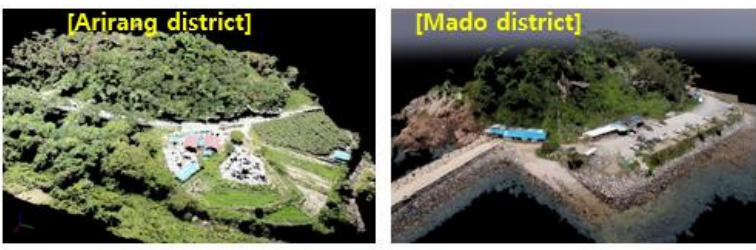

(a) Point clouds derived from drone mapping on study sites
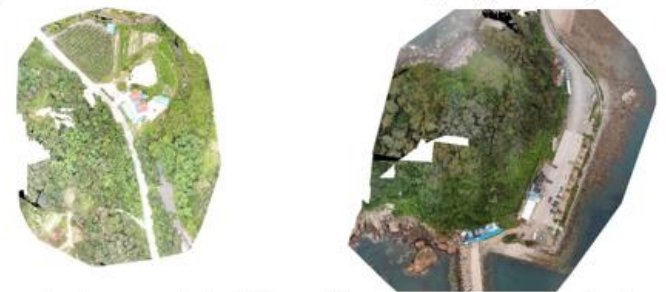

(b) ortho-images derived from drone mapping on study sites Figure 6. Drone mapping results 


\subsection{Slope risk analysis using Terrestrial LiDAR survey}

The integration of high performance multi-sensors mounted on small drones and high spatial resolution imaging enable UAVs expand its application fields as an observation platform. However, it has limitations to precisely observe the depth, width, and area of detailed cracks in bedrock by using the low point density of 3D point cloud generated by aerial imagery collected a constant flight altitude under the mountainous terrain or dangerous operation conditions in disaster sites. In other words, the spatial resolution and point density of point cloud derived from drone mapping is somewhat inadequate to precisely and quantitatively measure detailed crack information for slope risk analysis. Therefore, in this paper, we observed quantitative values related to the destruction or weathering of bedrock, which is difficult to observe in drone mapping, by measuring the slope through cross-sectional analysis of natural slopes using the Terrestrial LiDAR mounted on the investigation vehicle.

\subsubsection{Arirang site}

Using point cloud data of terrestrial LiDAR removed noise points such as tree, plant, facilities etc. around the slope, the slope pattern was analysed. The characteristics of observed steep slope were $86.69 \mathrm{~m}$ in total length, $17.77 \mathrm{~m}$ in maximum height, and $54^{\circ}(1: 0.73)$ in average slope. Weathered soil exists on the top of natural slope, which may cause to soil loss in the upper part due to concentrated heavy rain or long-term rainfall. As a result of analysis of the cross sections of major rock masses (A-A', B-B', C-C'), the joint slope of the rock mass is about $94^{\circ}$ to $107^{\circ}$. There is a high possibility of plane fracture due to regular joints, and a risk of rockfall due to loose rock mass.

\subsubsection{Mado site}

The dimensions of the target slope are $20.3 \mathrm{~m}$ in total length, $27.9 \mathrm{~m}$ in maximum height, and the average slope is $59^{\circ}(1: 0.60)$ The slope of middle section of bedrock is measured with a slope of about $70^{\circ}$, and there is revealed a natural slope with convex and complex shape. Weathering of bedrock seems to be in progress due to prolonged exposure, and joints and cracks loosening due to vegetation distributed over the entire slope were observed in many cases. The maximum protruding width of rock was about $4.1 \mathrm{~m}$.
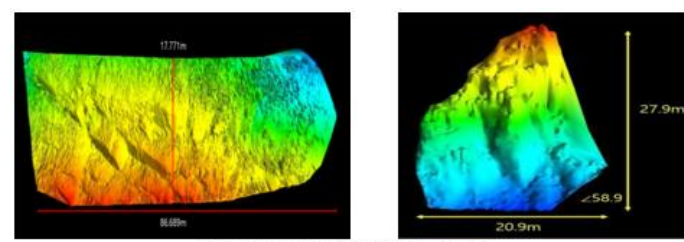

(a) Bedrock specification measuing

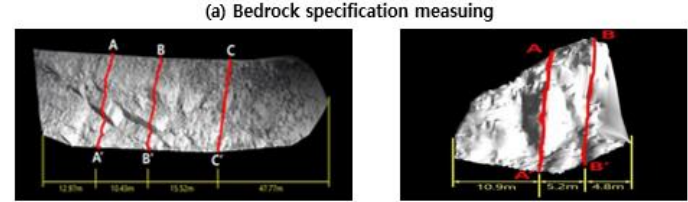

(b) Lacation of measured section profiles on target bedrock

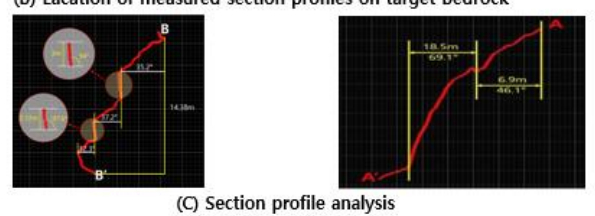

Figure 8. Section profile analysis results

\subsection{Risk assessment review}

\subsubsection{Arirang site}

In a comprehensive description through the results of observation with the visual inspection and survey equipment, Arirang site is judged as a natural rock slope and highly seems to cause the collapse of the slope or rockfall due to the joint group developed in the slope. This site is necessary to take constructive maintenance measures that can actively suppress collapse and rockfall (slope relief, reinforcement method, etc.). Many rockfalls are in progress on site that have fallen out of the rock mass of the section A-B on the slope, and the damaged rockfall fences are also required to be repaired.

To be worry, there is a heavy traffic movement of large construction vehicles on the adjacent roads, and secondary accidents may occur due to the rockfall of steep slope located on the curved pass where visibility is difficult to secure, so urgent and continuous safety management measures such as reinforcement of rockfall prevention facilities seem to be necessary.

\subsubsection{Mado site}

Mado site is a typical natural slope composed of rock mass and estimated that the overall strength is low due to the weathering of the surface, and cracks caused by vegetation has exist. Due to the high steep angle of about $70^{\circ}$ and unstable terrain conditions, the damage caused by rockfall is very concerned. Considering the size of the steep slope, it is judged that it is necessary to apply active suppression methods such as removal of rockfall-causing rocks, mitigation of inclination angles (blasting, trench, etc.) and application of reinforcement methods.

\section{CONCLUSIONS}

Due to abnormal weather caused by climate change in recently years, natural disaster damages caused by local torrential rains have been increased over the world. Particularly, Korea is very vulnerable to landslide disasters because more than $63 \%$ of the country is mountainous and it suffers from unpredictable localized heavy rainfall during monsoon season every year. In this paper, we acquired drone aerial imagery of steep slope site around and conducted a drone mapping to obtain 3D point clouds, DEM and ortho-imagery of the study area using the Pix4D software. For collecting the more detailed geological data and analysing quantitatively damage of steep slopes (crack length, bedrock weathering area, etc.), we scanned steep slope area using terrestrial LiDAR system. Finally, we evaluated the applicability of public safety for outputs of UAV photogrammetry and 3D point clouds derived from terrestrial LiDAR data to analyse and assess the risk of steep slope.

The use of state-of-the-art observation platform such as such as LiDAR mapping system and drones for topographic mapping will be expected to enable the collection of high-precision spatial information and analysis based on spatial information in the event of a natural disaster.

\section{ACKNOWLEDGEMENTS}

This research outputs are part of the project "Development of forensic techniques for Disaster Scientific Investigation", which is supported by the NDMI (National Disaster Management research Institute) under the project number NDMI-MA-202006-01. The authors would like to thank the financial support of the NDMI. 


\section{REFERENCES}

K. Eng, O., Strecha, C., Beyeler, A., Zufferey, JC, Floreano, D., Fua, P., Gervaix, F., 2011. The Accuracy of Automatic Photogrammetric Techniques on Ultra-Light Uav Imagery, International Archives of Photogrammetry, Remote Sensing and Spatial Information Sciences, Vol. XXXVIII-1 / C22, pp. 125130.

Kim, S.S., Song, B.G., Cho, S.B., Kim, H.J., 2019, Applicability of Drone Mapping for Natural Disaster Damage Investigation, Journal of Korean Society for Geospatial Information Science, Vol.27 No.2 March 2019 pp.13-21.

Kim, S. S., Kim, T. H., and Sim. J. S. 2019. Applicability Assessment of UAV Mapping for Disaster Damage Investigation in Korea. The International Archives of the Photogrammetry, Remote Sensing and Spatial Information Sciences, Volume XLII-3/W8, 2019 GeoInformation For Disaster Management (Gi4DM), 3-6 September 2019, Prague, Czech Republic. pp. 209-214.

Kim, S.S., Yoo, S.H., Park, J.S., Cho, S.B., Kim, T.H., 2018, Rapid Disaster Mapping through Data Integration from UAVs and Multi-sensors Mounted on Investigation Platforms of NDMI, Korea The International Archives of the Photogrammetry, Remote Sensing and Spatial Information Sciences, Volume XLII-3/W4, 2018 GeoInformation For Disaster Management (Gi4DM), 18-21 March 2018, Istanbul, Turkey.

Mian, O., Lutes, J., Lipa, G., Hutton, J.J., Gavelle, E., Borghini, s., 2015. Direct Geo-referencing on Small Unmanned Aerial Platforms for Improved Reliability and Accuracy of Mapping Without the Need for Ground Control Points, International Archives of the Photogrammetry, Remote Sensing and Spatial Information Science, Vol. XL-1/W4, UAV-g 2015, York University, Toronto, Canada.

Ministry of the Interior and Safety, 2018, Guidelines for Planning Natural Disaster Investigation and Recovery Plans 2018.

Oh, Y. O, Choi, K. A. and Lee, I. P., 2017, Disaster Damage Detection Using Drone Aerial Images, In 2017 Joint Fall Conference proceedings of the Korean Society for Geo-spatial Information Science, pp. 213-214.

Pix4D, 2019, Accuracy of Pix4D Outputs, https://support.pix4d.com/hc/en-us/articles/202558889-

Accuracy-of-Pix4D-outputs (last date accessed at 05 March

Rehak, M., Mibillard, R., Skaloud, J. 2013. A Micro-UAV with the Capability of Direct Georeferencing, International Archives of the Photogrammetry, Remote Sensing and Spatial Information Science, Vol. XL-1/W2, UAV-g 2013, Rostock, Germany.

Shin D. Y., Sim, J. S., Lee, K. S. 2019. Application of the steep slope risk assessment using the three dimensional spatial information data. The International Archives of the Photogrammetry, Remote Sensing and Spatial Information Sciences, Volume XLII-3/W8, 2019 GeoInformation For Disaster Management (Gi4DM), 3-6 September 2019, Prague, Czech Republic. pp. 381-386.

Turner, D., Lucieer, A., Wallace, L. 2013. Direct Georeferencing of Ultrahigh-Resolution UAV Imagery, IEEE
Transaction on Geoscience and Remote Sensing, 52(5): 27382745.

Verhoenven, G. 2011, Taking Computer Vision AloftArchaelological Three-dimensional Reconstructions from Aerial Photographs with Photoscan, Archaeological Prospection. 18, 67-73. 